Chaire de recherche sur les enjeux économiques intergénérationnels

\title{
Age-related taxation of bequests in the presence of a dependency risk
}

Marie-Louise Leroux and Pierre Pestieau

Cahier de recherche Working paper

Octobre / October 2020

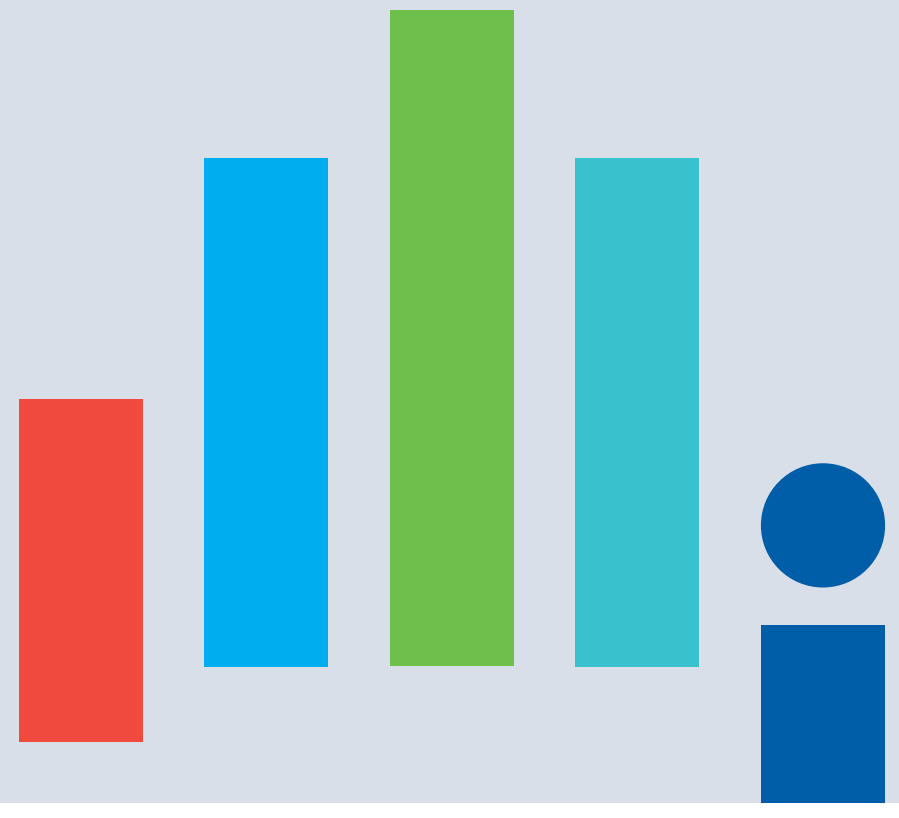


Les opinions et analyses contenues dans les cahiers de recherche de la Chaire ne peuvent en aucun cas être attribuées aux partenaires ni à la Chaire elle-même et elles n'engagent que leurs auteurs.

Opinions and analyses contained in the Chair's working papers cannot be attributed to the Chair or its partners and are the sole responsibility of the authors. 


\title{
Age-related taxation of bequests in the presence of a dependency risk ${ }^{1}$
}

\author{
Marie-Louise Leroux ${ }^{2}$ Pierre Pestieau ${ }^{3}$
}

October 2020

${ }^{1}$ The second author greatfully acknowledges funding from the Chaire « Marché des risques et création de valeur $»$ of the $\mathrm{FdR} / \mathrm{SCOR}$.

${ }^{2}$ Corresponding author. Département des Sciences Economiques, ESG-UQAM; CORE (UcL, Belgium); CESifo (Munich, Germany). E-mail: leroux.marie-louise@uqam.ca

${ }^{3}$ University of Liege, CORE, and Toulouse School of Economics. Financial support from the Chaire « Marché des risques et création de valeur» of the FdR/SCOR is gratefully acknowledged. 


\begin{abstract}
This paper studies the design of the optimal linear taxation of bequests when individuals differ in wage as well as in their risks of both mortality and old-age dependance. We assume that the government cannot distinguish between bequests motives, that is whether bequests resulted from precautionary reasons or from pure joy of giving reasons. Instead, we assume that it only observes the timing of bequests, that is whether they are made early in life or late in life.

We show that, if the government is utilitarian, whether the taxation of early bequests should be given priority over the taxation of late bequests depends on the magnitude of insurance and redistributive concerns. While the efficiency concern unambiguously recommends taxation of early bequests, redistributive concerns yield ambiguous results. This indeterminacy comes from the fact that, in case of late death, the government cannot observe the health status of the deceased. Whether the taxation of early bequests should be given priority depends on the specific relationships between wages and both risks of early death and of old-age dependence, as well as on the concavity of the joy of giving utility function. If the government is Rawlsian, it is optimal to tax early bequests if the survival chances of the poorest agents are very low. If they survive, but their chances to remain autonomous are very low, it is then optimal to tax early bequests if the poorest agents contribute relatively less to the taxation of early bequests than to the taxation of late bequests or if the joy of giving utility is extremely concave.
\end{abstract}

Keywords: Bequest taxation; Long term care; Utilitarianism; Rawlsian welfare criterion; Old-age dependency.

JEL Codes: H21, H23, I14. 


\section{Introduction}

In the recent years, the taxation of wealth transfers (including inheritance and inter vivos gifts) has been going through a bad patch. Revenue raised through taxes on inherited wealth has shrunk significantly over the last decades. In OECD countries, the proportion of total government revenues raised by such taxes has fallen from $1.1 \%$ in the mid-60s to $0.4 \%$ in 2017 (OECD, 2018). Over the same period, some countries like Australia, Israel, Mexico, Sweden and Norway have abolished death duties. One of the reasons for this state of disgrace may be the poor design of those taxes (through exemptions, deductions, and avoidance opportunities). The purpose of this paper is then to look at the optimal design of wealth transfer taxation, from both an efficiency and a redistributive perspective, in a realistic framework where older individuals with different revenues face a double risk, the risk of death and that of dependence.

Following Cremer and Pestieau (2006), the optimal wealth transfer tax structure crucially depends on the assumed bequest motives and, thus, on the type of bequests left by the deceased. Some bequests are purely accidental. Since agents do not know how long they will live, they may save more money than they turn out to need. In that situation, the taxation of accidental bequests is quite efficient and can even be redistributive. However, savings can also be motivated by the direct utility obtained from the act of giving (i.e. a "warm glow" motivation). In that case, bequests are voluntary and reflect the preference of the deceased to leave some money to their heirs so that inheritance taxation would end up being distortionary. Yet, it is often quite difficult to disentangle those bequest motives. Instead, governments only have information on the timing of bequests, i.e. whether these are made early or late in life, which in turn, provides some information regarding the motives of wealth transmission and on which they can condition taxation.

Hence, savings comprise two main components. On the one hand, part of individuals' savings aim at benefiting their heirs, out of altruism or joy of giving. On the other hand, part of individuals' savings are precautionary and, aim at covering old-age needs that cannot be (fully) insured against. In case of a healthy retirement, these needs correspond to expenses not covered by pensions and due to annuity market imperfections. In case of old-age dependence, these needs correspond to the (extra) costs of long-term care (LTC hereafter) that are not insured. When agents die prematurely or when they live long but healthy, precautionary savings are transmitted to their heirs even though this transmission was not the main motivation. In most societies, the risk of a too long life is better insured (for instance, through public or private annuitization) than the risk of dependence $\mathrm{H}^{1}$ In other words, one can expect that the precautionary savings related to the risk of dependence represent an important part of those unplanned bequests ${ }^{2}$

\footnotetext{
${ }^{1}$ In most OECD countries, the market for LTC insurance is still largely under-developed. See, for instance, Brown and Finkelstein (2009), Pestieau and Ponthiere (2011), OECD (2011).

${ }^{2}$ See Lockwood (2018) who shows that in presence of bequest motives, individuals prefer to make pre-
} 
So as to take into account these features, our paper models an economy where agents differ with respect to their labor productivity, their risk of mortality and their risk of dependence. Those who happen to die prematurely, bequeath all their savings (both the "warm glow" and the precautionary ones) to their children. Those who live long can be either healthy or dependent. It is most likely that those who are healthy can afford to transfer also part of their precautionary savings to their children. To the opposite, dependent agents will consume the entirety of their precautionary savings and, will only be able to bequeath the "joy of giving" part of their savings. Hence, the question we ask is the following: considering that agents with different incomes, face differentiated risks of longevity and of old-age dependence, should early bequests be taxed more heavily than late bequests?

This implicitly amounts to ask whether the taxation of bequests should be adapted so as to take into account the fact that agents need to make extra precautionary savings so as to insure against the dependency risk but, that this risk is not shared equally in the population.

To answer these questions, we assume a two-period model. Agents obtain utility from consumption and from bequeathing their wealth to their kids. The first period is certain, while individuals survive to the second period with some probability. In the first period, agents work and save for retirement and as well as for possible LTC expenditures. If they survive to the second period, they eventually become dependent, in which case they will need extra resources to finance LTC expenditures. Depending whether they die at the end of the first or of the second period, and on their health status at death, bequests will be more or less important depending on whether precautionary savings add up to the planned bequests.

As we will show, the resulting taxes will closely depend on the distribution of the three individual characteristics as well as on their correlations. In that respect, we use some stylized facts regarding the risks of mortality and of disability taken from Lefebvre et al. (2018). These authors use the data from the Survey on Health and Retirement in Europe (SHARE) to establish that the risks of early death and of dependence are both negatively correlated with income. Even though low-income people have a relatively shorter life, they also face a higher risk of dependence. As a consequence, we have two opposing forces when deciding the amount of individual savings and of planned bequests. On the one hand, poorer individuals are induced to save less (and give lower planned bequests) because of both lower income and lower survival probability. But, on the other hand, they are pushed to save more (and give higher planned bequests) because of a higher probability to become dependent. If the differences in income and in survival probability are higher than the differences in the probability to become dependent, we obtain that savings should increase with income.

As already mentioned, the government is unable to distinguish between planned and unplanned bequests, the latter depending on the health status of the individual as well as on whether he survived. The only information available to the government is the timing

cautionary savings rather than buying LTC insurance. 
of transmissions. Early transmissions always include both planned and unplanned bequests while late transmissions may or may not include unplanned bequests, depending on the health status of the deceased. Late transmissions when healthy are higher than late transmissions when dependent even though they cannot be distinguished between by the tax authority.

If the government only has access to restricted instruments such as taxes on early and late bequests, we find that the optimal tax policy of a utilitarian government depends both on efficiency and redistributive concerns. The efficiency concern relates to the objective of equalizing bequests across the different states of nature (i.e. for different length or life and different health status at old age), and it can be identified as an insurance motive. This unambiguously pushes toward higher taxation of early bequests relative to late ones. The redistributive motive, on the other hand, provides ambiguous recommendations as it depends on the specific relationships between wages and both risks of early death and of dependence. Because high-income agents more often live long and, when they survive, they are less often dependent, late taxation of bequests should be fostered. On the other hand, if they survive, low-income agents are more often dependent, which pushes against the taxation of late bequests, and toward higher taxation of early ones. One of the difficulty here, comes from the fact that, in case of late death, the government cannot condition the taxation of late bequests on the (unobservable) health status of the deceased. Nonetheless, if agents are very risk-averse to leaving different levels of bequests (because of different realized health status or length of life) to his heirs, the insurance effect dominates the redistributive effect, and we can conclude that taxing early bequests is optimal.

We finally compare our results with those obtained if the government were Rawlsian and, aimed at maximizing the utility of the least well-off agent. In that situation, and given the correlations between income and demographic characteristics, we obtain that it is optimal to tax more heavily early bequests, if the survival chances of the poorest agent are very low. Alternatively, if he survives, but his chances to remain autonomous are very low, it is then again optimal to tax early bequests if the (positive) insurance effect of increasing the taxation of early bequests for the poorest agents, dominates its (negative) revenue effect. This will be the case if the poorest agents contribute relatively less to the taxation of early bequests than to the taxation of late bequests or, if agents are very risk averse to leaving different levels of bequests.

Our paper can be related to at least three strands of the literature. First, it can be related to the vast literature on wealth transfer taxation (among others, Cremer et al. 2012; Pestieau and Sato, 2008; Brunner and Pech, 2012). This literature has shown how important it is to distinguish between the different motives that induce (heterogenous) agents to leave some bequests to their heirs and how it may affect the design of optimal wealth transfer taxation 3 Recently, Piketty and Saez (2013) and Garcia-Miralles (2020) have underlined

\footnotetext{
${ }^{3}$ See for instance Blumkin and Sadka (2003), Farhi and Werning (2013) and, for a survey, Cremer and
} 
the importance of considering alternative social welfare criteria on the optimal design of inheritance taxation in settings where individuals are heterogeneous in terms of bequests tastes, labour productivities and wealth. We use some of these insights in our model, by considering agents with different income and demographic characteristics, as well as different bequest motives and different social welfare criteria. Second, our paper can be related to the developing theoretical literature on the optimal design of LTC public policies. Like us, these papers often assume an heterogenous population of individuals. While we do not directly study the optimal form of the LTC public insurance system, as in Cremer and Pestieau (2014), Leroux et al. (2019), Nishimura and Pestieau (2016) for example, we show how bequest taxation can be reformed so as to take into account the growing reality that an increasing number of older agents may incur LTC expenses, for which they need to make precautionary savings $4^{4}$ Finally, it can be related to the (small) literature on the age-dependent taxation of bequests, initiated by Vickrey (1945). Some of the arguments in favour of a taxation of bequests varying with the age of the deceased are summarized in Pestieau and Ponthiere (2019). Fleurbaey et al. (2019) also study the optimal taxation of accidental bequests and show that the taxation of bequests should be increasing with the age of the deceased when the social objective is ex-post egalitarian, i.e. if it wants to neutralize any ex-post welfare inequality between agents with different lifespans. Nonetheless, none of these papers account for the possibility of old-age dependency, like we do.

Our paper is structured as follows. In the next section, we describe the model. Section 3 presents the first-best optimum, while Section 4 gives the second-best results. Section 5 discusses these results using a Rawlsian social welfare function. The last section concludes.

\section{The model}

\section{$2.1 \quad$ Assumptions}

We consider a society composed of $N$ types of individuals, indexed by $i=\{1, \ldots, N\}$, characterized by a wage $w_{i}$. Each group is in proportion $n_{i}$ with $\sum_{i} n_{i}=1$. Agents live two periods. The first one, let say young adulthood, is certain, while the second one, the retirement period, is uncertain. Agents survive to that second period with probability $0 \leq \pi_{i} \leq 1$. In case they survive, agents also face a different (conditional) probability to become dependent, denoted by $p_{i}$, with $0 \leq p_{i} \leq 1$.

Relying on Lefebvre et al. (2018), we assume a positive correlation between wage and survival, so that higher wage individuals face a higher survival probability. We also assume that they have a lower conditional probability to become dependent. Yet, combining those

Pestieau (2006).

${ }^{4}$ Cremer al. (2016) also study the optimal design of public LTC insurance which includes a linear tax on bequests. Yet, these can only be voluntary and are used by parents as a way to induce more informal care from children. 
two effects, the unconditional probability to become dependent, i.e. $\pi_{i} p_{i}$, is higher for lower wage than for higher wage, showing that the dependency effect (through $p_{i}$ ) dominates the survival effect (through $\pi_{i}$ ).

In the first period, agents supply one (fixed) unit of labour, consume an amount $c_{i}$ and save for their old age. They also determine how much income they would like to give to their offspring. If they survive, in the second period, they do not work anymore and, they consume an amount $d_{i}$ in case of autonomy, and an amount $m_{i}$ which include LTC expenditures, in case of dependency.

Individuals preferences are additively separable in consumptions and the amount of bequests:

$$
U_{i}=u\left(c_{i}\right)+\pi_{i} p_{i}\left[H\left(m_{i}\right)+v\left(b_{i}^{D}\right)\right]+\pi_{i}\left(1-p_{i}\right)\left[u\left(d_{i}\right)+v\left(b_{i}^{L}\right)\right]+\left(1-\pi_{i}\right) v\left(b_{i}^{E}\right)
$$

Utility of consumption under good health (equivalently autonomy), is denoted by $u($.$) while$ under bad health (i.e. dependency) is denoted by $H($.$) . As it is usual, these utilities are$ increasing and concave, i.e. $u^{\prime}() \geq 0,. u^{\prime \prime}() \leq$.0 and $H^{\prime}() \geq 0,. H^{\prime \prime}() \leq$.0 . For simplicity, we also assume that the utility in case of dependency takes the following form: $H(x)=u(x-\bar{L})$ where $\bar{L}$ is the monetary equivalent of the loss due to old-age dependency. This implies that marginal utility under dependence is higher than under autonomy: $H^{\prime}(x)=u^{\prime}(x-\bar{L})>$ $u^{\prime}(x)$.

The utility obtained from leaving some bequests is denoted $v\left(b_{i}^{j}\right)$ where $b_{i}^{j}$ represents the amount of bequest received by the offspring of agent $i$ and where $j=E, L, D$ stands for the timing of the bequests left by the agent, that is depending on whether the latter died early $(E)$, late in good health $(L)$ or late under dependence $(D) 5^{5}$ Note that in the following, we will assume that the deceased cares about the amount of bequests received by his heirs, i.e. net of taxation, and not about the gross amount (i.e. before taxation). We also assume that $v^{\prime}() \geq$.0 and $v^{\prime}() \leq$.0 .

\subsection{Laissez-faire}

We assume that there exists no private or public annuity market, and no LTC private or public insurance $\sqrt[6]{6}$ We also assume that the interest rate is zero and that individuals have no pure time preferences. The individual's problem is expressed as follows:

$$
\begin{aligned}
\max _{s_{i}, b_{i}, x_{i}} U_{i}= & u\left(w_{i}-s_{i}-b_{i}\right)+\pi_{i} p_{i}\left[H\left(s_{i}\right)+v\left(b_{i}\right)\right]+\left(1-\pi_{i}\right) v\left(b_{i}+s_{i}\right) \\
& +\pi_{i}\left(1-p_{i}\right)\left[u\left(s_{i}-x_{i}\right)+v\left(x_{i}+b_{i}\right)\right]
\end{aligned}
$$

\footnotetext{
${ }^{5}$ This can also be referred to as imperfect altruism.

${ }^{6}$ Assuming otherwise would not greatly modify our results. One difference would only be that, for some agents with low wages, private savings are nil. Here, we want to focus on the direct redistributive and efficiency effects of a variation in the bequest taxes without considering indirect effects through the distributive impacts of a public LTC or pension benefits. In addition, in reality, the LTC insurance market is almost inexistent (see OECD, 2011).
} 
where $s_{i}$ is private saving, $b_{i}$ is the amount of planned bequests, and $x_{i}$ is the extra amount the agent would leave to his offsprings in case the individual enjoys a healthy retirement period. By definition, $s_{i} \geq x_{i}$. Indeed, since we assume that there is no LTC insurance, as it is the case in many countries, individuals are forced to choose a level of precautionary savings higher than what would be needed if there was no risk to become dependent (i.e. $\left.p_{i}=0\right)$. Note that only in the case where the agent becomes dependent, he will leave exactly the planned bequest, $b_{i}$. If he dies early or late in good health, he will leave an extra amount, $s_{i}$ or $x_{i}$, which corresponds to some of the precautionary savings he had made to cover the risk of a long life either in good or in bad health.

The first-order conditions of the above problem are:

$$
\begin{aligned}
& \frac{\partial U_{i}}{\partial s_{i}}=-u^{\prime}\left(c_{i}\right)+\pi_{i} p_{i} H^{\prime}\left(s_{i}\right)+\pi_{i}\left(1-p_{i}\right) u^{\prime}\left(s_{i}-x_{i}\right)+\left(1-\pi_{i}\right) v^{\prime}\left(b_{i}+s_{i}\right)=0 \\
& \frac{\partial U_{i}}{\partial b_{i}}=-u^{\prime}\left(c_{i}\right)+\pi_{i} p_{i} v^{\prime}\left(b_{i}\right)+\left(1-\pi_{i}\right) v^{\prime}\left(b_{i}+s_{i}\right)+\pi_{i}\left(1-p_{i}\right) v^{\prime}\left(x_{i}+b_{i}\right)=0 \\
& \frac{\partial U_{i}}{\partial x_{i}}=-u^{\prime}\left(s_{i}-x_{i}\right)+v^{\prime}\left(x_{i}+b_{i}\right)=0
\end{aligned}
$$

From the last condition, we obtain that in case of good health at the old age, the extra amount of savings $x_{i}$ left to offsprings should be set so as to equalize the marginal utility from consumption with the marginal utility from leaving some bequests, i.e. $u^{\prime}\left(s_{i}-x_{i}\right)=$ $v^{\prime}\left(x_{i}+b_{i}\right)$. Replacing for this equality in the FOCs (2) and (3), we also obtain that the marginal utility of consumption under dependence should be equalized to the marginal utility from leaving some bequests when dependent at the old age, i.e. $H^{\prime}\left(s_{i}\right)=v^{\prime}\left(b_{i}\right)$.

Let us now make some comparative statics with respect to the wage $w_{i}$, the survival probability $\pi_{i}$ and the conditional probability to become dependent, $p_{i}$. Considering the above first-order conditions, one can immediately see that the implicit function theorem cannot be used since each FOC includes the other endogenous variables. Instead, one needs to use the Cramer's rule which proves difficult with three equations and three unknowns and would certainly result in ambiguous effects. Hence, in order to deal with this issue, when making the comparative statics analysis, we are going to consider only the direct effects of $w_{i}, \pi_{i}$ and $p_{i}$ on successively $s_{i}, b_{i}$ and $x_{i}$, assuming that indirect effects (i.e. through the variation of the other endogenous variables) are negligible or zero. $]^{7}$ As it is clear from the last FOC, there is no direct effect of $w_{i}, \pi_{i}$ and $p_{i}$ on $x_{i}$ but only indirect effects. The variations of $x_{i}$ result from the joint variations of $b_{i}$ and $s_{i}$ with respect to these parameters. Also, one can already show from condition $H^{\prime}\left(s_{i}\right)=v^{\prime}\left(b_{i}\right)$, that the variations of $s_{i}$ and $b_{i}$ with respect to $w_{i}, \pi_{i}$ and $p_{i}$ have the same sign.

Partially differentiating (2) with respect to $w_{i}$, we find that, saving $s_{i}$ (and thus, the planned bequests $\left.b_{i}\right)$ are increasing in $w_{i}$. Also, using the equalities $H^{\prime}\left(s_{i}\right)=v^{\prime}\left(b_{i}\right)$ and

\footnotetext{
${ }^{7}$ This amounts to applying the implicit function theorem, by treating the other endogenous variables as exogenous.
} 
$u^{\prime}\left(s_{i}-x_{i}\right)=v^{\prime}\left(x_{i}+b_{i}\right)$, we obtain that $s_{i}$ (and thus, $\left.b_{i}\right)$ are increasing in $\pi_{i}$ and $p_{i}$. Hence, on the one hand, richer individuals save more (and give higher planned bequests) because of higher income and higher survival probability. But, on the other hand, they are pushed to save less (and give lower planned bequests) because of a lower conditional probability to become dependent. If the differences in income and in survival probability are higher than the differences in the probability to become dependent, we obtain that savings should increase with income.

Our results are summarized in the following proposition:

Proposition 1 Suppose an economy where agents differ in income and where income and survival probability are positively correlated while income and dependency probability are negatively correlated. The laissez-faire allocation yields that

- savings and planned bequests are increasing in income, survival probability, and in the probability to become dependent.

- If differences in incomes and survival dominate differences in the probability to become dependent, higher-income agents save more and leave more bequests than lower-income ones.

\section{The first-best optimum}

To start with, we assume a utilitarian government 8 His problem therefore consists in maximizing the sum of individuals' utility subject to the resource constraint of the economy:

$$
\begin{aligned}
\max _{c_{i}, d_{i}, m_{i}, b_{i}^{D}, b_{i}^{L}, b_{i}^{E}} \sum_{i} n_{i} U_{i}= & \sum_{i} n_{i}\left\{u\left(c_{i}\right)+\pi_{i} p_{i}\left[H\left(m_{i}\right)+v\left(b_{i}^{D}\right)\right]\right. \\
& \left.+\pi_{i}\left(1-p_{i}\right)\left[u\left(d_{i}\right)+v\left(b_{i}^{L}\right)\right]+\left(1-\pi_{i}\right) v\left(b_{i}^{E}\right)\right\} \\
\text { s. to } \sum_{i} n_{i} w_{i} \geq & \sum_{i} n_{i}\left\{c_{i}+\pi_{i} p_{i}\left(m_{i}+b_{i}^{D}\right)+\pi_{i}\left(1-p_{i}\right)\left(d_{i}+b_{i}^{L}\right)+\left(1-\pi_{i}\right) b_{i}^{E}\right\}
\end{aligned}
$$

Rearranging the FOCs of this problem, we obtain the following trade-offs:

$$
\begin{aligned}
& u^{\prime}\left(c_{i}\right)=u^{\prime}\left(d_{i}\right)=H^{\prime}\left(m_{i}\right) \forall i \\
& v^{\prime}\left(b_{i}^{D}\right)=v^{\prime}\left(b_{i}^{L}\right)=v^{\prime}\left(b_{i}^{E}\right) \forall i
\end{aligned}
$$

Hence, at the first-best optimum, it is optimal to equalize consumptions in good health in the first and the second periods, and to provide higher consumption in case of dependency. It is also optimal to set the level of consumptions identical across individuals with different wages, so that $m_{i}=\bar{m}>c_{i}=d_{i}=\bar{c}$.

\footnotetext{
${ }^{8}$ In Section 4.3 we assume instead a Rawlsian government.
} 
Regarding the level of bequests, it is optimal to set them at the same level independently from whether the agent lives long or dies early, and whether he remains autonomous or dependent 9 It should also be equalized across agents with different wages so that $b_{i}^{D}=$ $b_{i}^{L}=b_{i}^{E}=b$.

It is straightforward to show that this first-best optimum can be implemented by making the appropriate individualized lump sum transfers, so as to ensure equality of consumptions, LTC expenditures and voluntary bequests across individuals with different wages and demographic characteristics.

Our results are summarized in the following proposition.

Proposition 2 Suppose an economy with agents differing in income, survival probability and probability to become dependent. At the first-best utilitarian optimum, we obtain that

- per period consumption is equalized across agents,

- consumption when dependent is higher than when autonomous,

- bequests are equalized across agents, and independent of either the timing or the health state of the deceased.

\section{The second-best optimum}

In this section, we now assume that the government cannot use individualized lump sum transfers anymore but that he can only use restricted (linear) instruments so as to implement the optimum, as in Sheshinski (1972).

We will therefore assume the following policy instruments: a uniform lump sum transfer $T$ given to the individual in the first period, and a system of age-differentiated taxes on bequests, $\left\{\tau_{E}, \tau_{L}\right\}$. The tax $\tau_{E}$ corresponds to the tax on early bequests, that is on bequests left by the deceased if he dies at the end of the first period while the $\operatorname{tax} \tau_{L}$ corresponds to the tax on late bequests, that is on bequests left by the deceased if he dies at the end of the second period 10 Note that the $\operatorname{tax} \tau_{L}$ does not depend on the health status of the elderly. This assumption that the tax cannot be differentiated according to the health status is made here for three reasons. In real economies, the taxation of bequests does not depend on the health condition of the deceased. Second, the health status of the elderly may be difficult to observe. Third, it may be politically difficult to implement taxes that depend on something for which the individual cannot be held responsible of, i.e. his health status at the old age.

\footnotetext{
${ }^{9}$ This is due to the separability of preferences between consumption and bequests.

${ }^{10}$ Whether the tax is paid by the deceased or the descendant does not matter here as we assume that the utility obtained from bequeathing wealth is net of taxation.
} 


\subsection{The individual's problem}

The problem of an individual with type $i$, facing the public policy instruments $\left(T, \tau_{E}, \tau_{L}\right)$ is now modified in the following way:

$$
\begin{aligned}
\max _{s_{i}, b_{i}, x_{i}} U_{i}= & u\left(w_{i}-s_{i}-b_{i}+T\right)+\pi_{i} p_{i}\left[H\left(s_{i}\right)+v\left(\left(1-\tau_{L}\right) b_{i}\right)\right]+\left(1-\pi_{i}\right) v\left(\left(1-\tau_{E}\right)\left(b_{i}+s_{i}\right)\right) \\
& +\pi_{i}\left(1-p_{i}\right)\left[u\left(s_{i}-x_{i}\right)+v\left(\left(1-\tau_{L}\right)\left(x_{i}+b_{i}\right)\right]\right.
\end{aligned}
$$

In the following, we will distinguish between three levels of bequests, net of taxation, received by the offspring of agent $i$ and, denote them as follows: $b_{i}^{E}=\left(b_{i}+s_{i}\right)\left(1-\tau_{E}\right)$ in case of early death, $b_{i}^{L}=\left(b_{i}+x_{i}\right)\left(1-\tau_{L}\right)$ in case of a healthy long life and $b_{i}^{D}=b_{i}\left(1-\tau_{L}\right)$ in case of dependency. Recall also that, because agents care about the amount received by their heirs, the levels of taxation $\tau_{E}$ and $\tau_{L}$ appear in the function $v($.$) .$

The first-order conditions of the above problem are:

$$
\begin{aligned}
\frac{\partial U_{i}}{\partial s_{i}} & =-u^{\prime}\left(c_{i}\right)+\pi_{i} p_{i} H^{\prime}\left(s_{i}\right)+\pi_{i}\left(1-p_{i}\right) u^{\prime}\left(s_{i}-x_{i}\right)+\left(1-\pi_{i}\right) v^{\prime}\left(b_{i}^{E}\right)\left(1-\tau_{E}\right)=0 \\
\frac{\partial U_{i}}{\partial b_{i}} & =-u^{\prime}\left(c_{i}\right)+\pi_{i} p_{i} v^{\prime}\left(b_{i}^{D}\right)\left(1-\tau_{L}\right)+\left(1-\pi_{i}\right) v^{\prime}\left(b_{i}^{E}\right)\left(1-\tau_{E}\right)+\pi_{i}\left(1-p_{i}\right) v^{\prime}\left(b_{i}^{L}\right)\left(1-\tau_{L}\right)=0 \\
\frac{\partial U_{i}}{\partial x_{i}} & =-u^{\prime}\left(s_{i}-x_{i}\right)+v^{\prime}\left(b_{i}^{L}\right)\left(1-\tau_{L}\right)=0
\end{aligned}
$$

These conditions jointly determine the levels of savings and bequests, as a function of the policy instruments. For the following, we denote these demand functions by $s_{i}^{*}\left(T, \tau_{E}, \tau_{L}\right)$, $b_{i}^{*}\left(T, \tau_{E}, \tau_{L}\right)$ and $x_{i}^{*}\left(T, \tau_{E}, \tau_{L}\right)$.

\subsection{The optimal second-best policy.}

As already mentioned, the government only observes the period at which bequests are left by the agent to his offspring, so that taxation can only be conditioned on whether bequests happen early or late in life.

The problem of the utilitarian government consists in choosing the level of policy instruments so as to solve the following problem:

$$
\begin{array}{rll}
\max _{T, \tau_{L}, \tau_{E}} & E & \left\{u\left(w-s^{*}-b^{*}+T\right)+\pi p\left[H\left(s^{*}\right)+v\left(\left(1-\tau_{L}\right) b^{*}\right)\right]\right. \\
+ & \pi(1-p)\left[u\left(s^{*}-x^{*}\right)+v\left(\left(1-\tau_{L}\right)\left(x^{*}+b^{*}\right)\right)\right] \\
+ & \left.(1-\pi) v\left(\left(1-\tau_{E}\right)\left(b^{*}+s^{*}\right)\right)\right\} \\
\text { s.to } & E\left\{\pi \tau_{L}\left(p b^{*}+(1-p)\left(b^{*}+x^{*}\right)\right)+(1-\pi) \tau_{E}\left(s^{*}+b^{*}\right)\right\} \geq T
\end{array}
$$

where, for simplicity, we replaced $\sum_{i} n_{i}$ by the expectation operator $E($.$) and we have$ dropped the arguments and indexes in the functions $s^{*}, b^{*}$ and $x^{*}$. 
Denoting the Lagrange multiplier associated with the revenue constraint of the government by $\mu$, and using the Envelop Theorem for $s^{*}, b^{*}$ and $x^{*}$, we obtain the following FOCs:

$$
\begin{aligned}
\frac{\partial \mathcal{L}}{\partial T} & =E u^{\prime}(c)-\mu\left[1-\Phi_{T}\right]=0 \\
\frac{\partial \mathcal{L}}{\partial \tau_{L}} & =-E \pi p b^{*} v^{\prime}\left(b^{D *}\right)-E \pi(1-p)\left(b^{*}+x^{*}\right) v^{\prime}\left(b^{L *}\right)+\mu\left\{E \pi p b^{*}+E \pi(1-p)\left(b^{*}+x^{*}\right)+\Phi_{\tau_{L}}\right\}=0 \\
\frac{\partial \mathcal{L}}{\partial \tau_{E}} & =-E(1-\pi) v^{\prime}\left(b^{E *}\right)\left(b^{*}+s^{*}\right)+\mu\left\{E(1-\pi)\left(s^{*}+b^{*}\right)+\Phi_{\tau_{E}}\right\}=0
\end{aligned}
$$

where $\Phi_{z} \equiv \tau_{L}\left(E \pi p \frac{\partial b^{*}}{\partial z}+E \pi(1-p) \frac{\partial\left(x^{*}+b^{*}\right)}{\partial z}\right)-\tau_{E} E(1-\pi) \frac{\partial\left(s^{*}+b^{*}\right)}{\partial z}$ represents the indirect effects (through $s^{*}\left(T, \tau_{E}, \tau_{L}\right), b^{*}\left(T, \tau_{E}, \tau_{L}\right)$ and $\left.x^{*}\left(T, \tau_{E}, \tau_{L}\right)\right)$ that the tax instrument $z=$ $\left\{T, \tau_{E}, \tau_{L}\right\}$ has on public revenue.

Let us now compute the condition defining the optimal level of $\tau_{E}$. To do so, we combine the last two FOCs and write down the derivative of the Lagrangian with respect to the tax on early bequests in compensated terms as follows:

$$
\frac{\partial \tilde{\mathcal{L}}}{\partial \tau_{E}}=\frac{\partial \mathcal{L}}{\partial \tau_{E}}+\frac{\partial \mathcal{L}}{\partial \tau_{L}} \frac{d \tau_{L}}{d \tau_{E}}
$$

where, from the budget constraint of the government, we obtain:

$$
\frac{d \tau_{L}}{d \tau_{E}}=-\frac{E(1-\pi)\left(s^{*}+b^{*}\right)}{E \pi p b^{*}+E \pi(1-p)\left(b^{*}+x^{*}\right)} .
$$

The above equation (7) enables to find the compensated effect of the tax on early bequests on welfare, that is, it enables to find whether a marginal change of $\tau_{E}$ would be beneficial to aggregate welfare, when that change is compensated by a variation of $\tau_{L}$ in order to maintain the government's budget balanced, as shown in equation (8).

Equation (7) can be rewritten as follows:

$$
\begin{aligned}
\frac{\partial \tilde{\mathcal{L}}}{\partial \tau_{E}}= & \quad\left[E \pi p b^{*} v^{\prime}\left(b^{D *}\right)+E \pi(1-p)\left(b^{*}+x^{*}\right) v^{\prime}\left(b^{L *}\right)\right] \frac{E(1-\pi)\left(s^{*}+b^{*}\right)}{E \pi p b^{*}+E \pi(1-p)\left(b^{*}+x^{*}\right)} \\
- & E(1-\pi) v^{\prime}\left(b^{E *}\right)\left(b^{*}+s^{*}\right)+\mu \tilde{\Phi}_{\tau_{E}}=0
\end{aligned}
$$

where $\frac{\partial \tilde{b}^{*}}{\partial \tau_{E}}=\frac{\partial b^{*}}{\partial \tau_{E}}+\frac{\partial b^{*}}{\partial \tau_{L}} \frac{d \tau_{L}}{d \tau_{E}}, \frac{\partial \tilde{s}^{*}}{\partial \tau_{E}}=\frac{\partial s^{*}}{\partial \tau_{E}}+\frac{\partial s^{*}}{\partial \tau_{L}} \frac{d \tau_{L}}{d \tau_{E}}$ and $\frac{\partial \tilde{x}^{*}}{\partial \tau_{E}}=\frac{\partial x^{*}}{\partial \tau_{E}}+\frac{\partial x^{*}}{\partial \tau_{L}} \frac{d \tau_{L}}{d \tau_{E}}$ stand for the compensated effects of the tax on early bequest on the amount of planned bequest, $b^{*}$, savings $s^{*}$ and $x^{*}$, and $\tilde{\Phi}_{\tau_{E}}$ corresponds to the expression $\Phi_{\tau_{E}}$ expressed in compensated terms. 
In order to find whether an increase in the taxation of early bequests (together with a decrease of late bequests taxation so as to keep the budget balanced) should be fostered, in the following, we study the increase in $\tau_{E}$ starting from an initial situation where both bequest taxes are null. Setting $\tau_{E}=\tau_{L}=0$, we obtain that $\tilde{\Phi}_{\tau_{E}}=0$ and the above expression can be rearranged as follows:

$$
\begin{aligned}
& \left.\frac{\partial \tilde{\mathcal{L}}}{\partial \tau_{L}}\right|_{\tau_{E}=\tau_{L}=0}=-\operatorname{cov}\left[(1-\pi) b^{E *}, v^{\prime}\left(b^{E *}\right)\right] \\
+ & \frac{E(1-\pi) b^{E *}}{E \pi p b^{D *}+E \pi(1-p) b^{L *}}\left[\operatorname{cov}\left[\pi p b^{D *}, v^{\prime}\left(b^{D *}\right)\right]+\operatorname{cov}\left[\pi(1-p) b^{L *}, v^{\prime}\left(b^{L *}\right)\right]\right] \\
+ & \frac{E(1-\pi) b^{E *}}{E \pi p b^{D *}+E \pi(1-p) b^{L *}}\left\{E\left[v^{\prime}\left(b^{L *}\right)-v^{\prime}\left(b^{E *}\right)\right] E \pi(1-p) b^{L *}+E\left[v^{\prime}\left(b^{D *}\right)-v^{\prime}\left(b^{E *}\right)\right] E \pi p b^{D *}\right\}
\end{aligned}
$$

where $b^{D *}=b^{*}, b^{L *}=b^{*}+x^{*}$ and, $b^{E *}=b^{*}+s^{*}$ in the specific case where $\tau_{E}=\tau_{L}=0$ and are such that $b^{E *}>b^{L *}>b^{D *}$.

The right-hand-side of this expression comprises five terms that we can now interpret. The first three terms, which include covariances, account for the redistributive effects of early bequests taxation on aggregate welfare, while the last two terms represent its efficiency effects (equivalently, the insurance effects) since, in a first best world, it would be desirable to equate these three levels of bequests and make them independent from the realized state of nature (i.e. on realized health and longevity).

Let us first focus on these last two terms. Since $b^{E *}>b^{L *}>b^{D *}$, they are both positive. This implies that, if individuals all had the same $w_{i}$, all the covariance terms (i.e. the three first terms) would be nil and thus, it would be desirable to tax early bequests (and to subsidize late bequests). This would enable to get closer to the first best situation where it is optimal to set $b^{E *}=b^{L *}=b^{D *}$ for all agents. Note also that if the concavity of the joy of giving utility $v($.$) is extreme, we obtain that the insurance terms are large so that they$ are very likely to dominate the redistributive terms. In that case, it is desirable to tax early bequests because individuals are very averse to leaving different amounts of bequests.

Let us then turn to the three covariance terms, which correspond to the equity terms. To interpret them, we use our stylized facts regarding the relations between $w_{i}, \pi_{i}, \pi_{i}\left(1-p_{i}\right)$, and $\pi_{i} p_{i}$ (see Section 2.1). We also use the fact that bequests (through the levels $s^{*}, x^{*}$, and $\left.b^{*}\right)$ are normal goods. The easiest covariance to sign is $\operatorname{cov}\left(\pi(1-p) b^{L *}, v^{\prime}\left(b^{L *}\right)\right)$, which is negative since $\pi_{i}\left(1-p_{i}\right)$ is higher for higher wages. This clearly pushes toward a lower level of early bequest taxation (equivalently, starting from a zero taxation of early bequests, toward subsidizing them), and hence, toward higher taxation of late bequests. Indeed, early bequests are more often made by the low-income agents who have a higher probability to die early, while late bequests are made by the long-lived and healthy individuals, who are 
more often high-wage individuals. These differences call for some redistributive taxation and subsidizing early bequests is a way to do so.

To the opposite, the sign of $\operatorname{cov}\left(\pi p b^{D *}, v^{\prime}\left(b^{D *}\right)\right)$ may be positive or negative since highwage individuals have a lower unconditional probability $\pi_{i} p_{i}$ to become dependent but $b_{i}^{D *}$ is higher for them. If the relationship between wages and the unconditional probability is strong and /or if $b_{i}^{D *}$ is poorly elastic to $w_{i}$, this covariance would turn out to be positive, which would push toward the taxation of early bequests (and thus, toward the subsidization of late bequests). Doing so would enable to redistribute more resources toward the long-lived dependent agents, who are also more often the low-income ones.

Finally, the sign of $\operatorname{cov}\left((1-\pi) b^{E *}, v^{\prime}\left(b^{E *}\right)\right)$ is also ambiguous since poor people have a higher probability $\left(1-\pi_{i}\right)$ to die at the end of the first period but $b_{i}^{E *}$ is smaller for them. Again, if $b_{i}^{E *}$ is poorly elastic to $w_{i}$ and given that low-income agents have a relatively higher mortality rate, this covariance would be positive, pushing toward a lower tax on early bequests (i.e., starting from $\tau_{E}=0$, toward a subsidy). The reason is similar as above. Since low-income agents are more often the ones to die early, equity motives push toward a lower taxation of early bequests, since low-income agents are more often the ones who leave early bequests.

Note also that the last two covariance terms and the insurance term, in equation (9) are weighted by

$$
\frac{E(1-\pi) b^{E *}}{E \pi p b^{D *}+E \pi(1-p) b^{L *}},
$$

which corresponds to a rewriting of equation (8) (in absolute value terms). In the following, we will denote this expression by $C$, and will refer to it as the "compensation factor" that allows to translate the effect of a variation of $\tau_{E}$ on $\tau_{L}$ so as to keep the government's budget balanced. It corresponds to the ratio of the early bequests tax base over the late bequests tax base, and it is most likely to be smaller than one ${ }^{11}$ As it is clear from equation $(9)$, this compensation factor also has to be taken into account when computing the overall sign of the equity terms, in order to see the desirability of increasing the taxation of early bequests.

Our results are summarized in the following proposition:

Proposition 3 Assume that the Utilitarian government can only use uniform lump sum transfers as well as linear taxes on early bequests and on late bequests. Assume also that he cannot observe the health status of the deceased. The second-best optimal policy is such that

- For efficiency reasons, the taxation of early bequests would be desirable.

- For equity reasons, the positive correlation between income and the probability to remain autonomous pushes toward subsidization of early bequests and taxation of late bequests.

\footnotetext{
${ }^{11}$ To see this, recall that agents who plan to live long $\left(\pi_{i}\right.$ large) have planned large bequests $\left(b_{i}^{D *}\right.$ and $b_{i}^{L *}$ large). We also have that, in developed economies, for all agent $i, \pi_{i}$ is in general relatively large.
} 
- For equity reasons, the negative correlation between income and the probability to become dependent pushes toward subsidization of late bequests and taxation of early bequests.

- For equity reasons, the positive correlation between income and survival pushes toward taxation of late bequests and subsidization of early bequests.

- If the joy of giving utility function $v($.$) is very concave, the insurance effects dominate$ the redistributive effects, and it is optimal to tax early bequests.

All in all, for reasonable levels of concavity of the the joy of giving utility, whether a tax on early bequests is desirable depends on the combined effects of the three covariance terms as well as on the efficiency effect. As we showed, the insurance effect pushes toward the taxation of early bequests. Yet, the overall equity effect is indeterminate and results both from the statistical relationships between wages, survival probability and the risk of dependence, and from the fact that the taxation of late bequests does not differentiate between bequests left by a dependent or by a healthy long-lived agent. On the one hand, because high-income agents are more often long-lived and more often in good health when they survive than lowincome agents, the government should prioritize taxation of late bequests (and subsidize early bequests). On the other hand, if they survive, low-income agents are more often dependent, so that taxation of late bequests (which cannot differentiate between healthy high-wage and dependent low-wage agents) is not desirable either and, taxation of early bequests should be preferred. Nonetheless, if agents are very risk-averse to leaving different levels of bequests to his heirs, we can conclude that early taxation of bequests is desirable.

\subsection{The maximin solution}

Let us now modify the above problem by considering instead a Rawlsian government and see whether we can obtain clearer results. The problem of the government now consists in maximizing the welfare of the worst-off individual, subject to the revenue constraint of the government. Here, the worst-off individual corresponds to the individual with the lowest wage denoted by $w_{0}$, and thus, the lowest survival probability $\pi_{0}$ and the highest unconditional probability $\pi_{0} p_{0}$ to become dependent. The problem now writes as follows:

$$
\begin{array}{ll}
\max _{T, \tau_{L}, \tau_{E}} \quad & u\left(w_{0}-s_{0}^{*}-b_{0}^{*}+T\right)+\pi_{0} p_{0}\left[H\left(s_{0}^{*}\right)+v\left(\left(1-\tau_{L}\right) b_{0}^{*}\right)\right] \\
+ & \pi_{0}\left(1-p_{0}\right)\left[u\left(s_{0}^{*}-x_{0}^{*}\right)+v\left(\left(1-\tau_{L}\right)\left(x_{0}^{*}+b_{0}^{*}\right)\right)\right]+\left(1-\pi_{0}\right) v\left(\left(1-\tau_{E}\right)\left(b_{0}^{*}+s_{0}^{*}\right)\right) \\
\text { s. to } & E\left\{\pi \tau_{L}\left(p b^{*}+(1-p)\left(b^{*}+x^{*}\right)\right)+(1-\pi) \tau_{E}\left(s^{*}+b^{*}\right)\right\} \geq T
\end{array}
$$


Using the Envelop Theorem for $s_{0}^{*}, b_{0}^{*}$ and $x_{0}^{*}$, the FOCs are now:

$$
\begin{aligned}
\frac{\partial \mathcal{L}}{\partial T}= & u^{\prime}\left(c_{0}^{*}\right)-\mu\left[1-\tau_{L}\left(E \pi p \frac{\partial b^{*}}{\partial T}+E \pi(1-p) \frac{\partial\left(x^{*}+b^{*}\right)}{\partial T}\right)-\tau_{E} E(1-\pi) \frac{\partial\left(s^{*}+b^{*}\right)}{\partial T}\right]=0 \\
\frac{\partial \mathcal{L}}{\partial \tau_{L}}= & -\pi_{0} p_{0} b_{0}^{*} v^{\prime}\left(b_{0}^{D *}\right)-\pi_{0}\left(1-p_{0}\right)\left(b_{0}^{*}+x_{0}^{*}\right) v^{\prime}\left(b_{0}^{L *}\right) \\
+\quad & \mu\left\{E \pi p b^{*}+E \pi(1-p)\left(b^{*}+x^{*}\right)+\tau_{L}\left(E \pi p \frac{\partial b^{*}}{\partial \tau_{L}}+E \pi(1-p) \frac{\partial\left(x^{*}+b^{*}\right)}{\partial \tau_{L}}\right)\right. \\
& \left.+\tau_{E} E(1-\pi) \frac{\partial\left(s^{*}+b^{*}\right)}{\partial \tau_{L}}\right\}=0 \\
\frac{\partial \mathcal{L}}{\partial \tau_{E}}= & -\left(1-\pi_{0}\right) v^{\prime}\left(b_{0}^{E *}\right)\left(b_{0}^{*}+s_{0}^{*}\right) \\
+ & \mu\left\{E(1-\pi)\left(s^{*}+b^{*}\right)+\tau_{L}\left(E \pi p \frac{\partial b^{*}}{\partial \tau_{E}}+E \pi(1-p) \frac{\partial\left(x^{*}+b^{*}\right)}{\partial \tau_{E}}\right)+\tau_{E} E(1-\pi) \frac{\partial\left(s^{*}+b^{*}\right)}{\partial \tau_{E}}\right\}=0
\end{aligned}
$$

Using the same procedure as in the previous section, we compute the marginal effect of an increase in $\tau_{E}$ on the welfare of the poorest agent in compensated terms:

$$
\begin{aligned}
\frac{\partial \tilde{\mathcal{L}}}{\partial \tau_{E}}= & {\left[\pi_{0} p_{0} b_{0}^{*} v^{\prime}\left(b_{0}^{D *}\right)+\pi_{0}\left(1-p_{0}\right)\left(b_{0}^{*}+x_{0}^{*}\right) v^{\prime}\left(b_{0}^{L *}\right)\right] \frac{E(1-\pi)\left(s^{*}+b^{*}\right)}{E \pi p b^{*}+E \pi(1-p)\left(b^{*}+x^{*}\right)} } \\
- & \left(1-\pi_{0}\right) v^{\prime}\left(b_{0}^{E *}\right)\left(b_{0}^{*}+s_{0}^{*}\right) \\
+ & \mu\left[\tau_{L}\left(E \pi p \frac{\partial \tilde{b}^{*}}{\partial \tau_{E}}+E \pi(1-p) \frac{\partial\left(\tilde{x}^{*}+\tilde{b}^{*}\right)}{\partial \tau_{E}}\right)+\tau_{E} E(1-\pi) \frac{\partial\left(\tilde{s}^{*}+\tilde{b}^{*}\right)}{\partial \tau_{E}}\right]=0
\end{aligned}
$$

Setting $\tau_{E}=\tau_{L}=0$, the above expression simplifies to:

$$
\left.\frac{\partial \tilde{\mathcal{L}}}{\partial \tau_{E}}\right|_{\tau_{E}=\tau_{L}=0}=\left[\pi_{0} p_{0} b_{0}^{D *} v^{\prime}\left(b_{0}^{D *}\right)+\pi_{0}\left(1-p_{0}\right) b_{0}^{L *} v^{\prime}\left(b_{0}^{L *}\right)\right] C-\left(1-\pi_{0}\right) v^{\prime}\left(b_{0}^{E *}\right) b_{0}^{E *}
$$

where $b_{0}^{D *}=b_{0}^{*}, b_{0}^{L *}=b_{0}^{*}+x_{0}^{*}, b_{0}^{E *}=b_{0}^{*}+s_{0}^{*}$ and the compensation factor $C$ is defined by (10). Again, the sign of this expression is ambiguous and crucially depends both the concavity of the function $v($.$) as well as on the specific levels of \pi_{0}$ and $p_{0}$. For that reason, it is not clear whether taxation of early bequests should be fostered in comparison to the taxation of late bequests.

In order to better understand the different mechanisms at play in this formula, let us assume first that the survival probability of the low-wage individual tends to 0 . In that situation where $\pi_{0} \rightarrow 0$, equation (11) simplifies to

$$
\left.\frac{\partial \tilde{\mathcal{L}}}{\partial \tau_{E}}\right|_{\tau_{E}=\tau_{L}=0}=-v^{\prime}\left(b_{0}^{E *}\right) b_{0}^{E *}<0
$$


so that, if low-wage individuals were (almost) certain to die at the end of the first period, it would be optimal to subsidize early taxation as a way to redistribute resources toward them.

Let us now instead assume that $0<\pi_{0}<1$, but $p_{0} \rightarrow 1$ so that if the lowest-income agents survive, they are (almost) certain to become dependent. In that case, equation (11) becomes

$$
\left.\frac{\partial \tilde{\mathcal{L}}}{\partial \tau_{E}}\right|_{\tau_{E}=\tau_{L}=0}=\pi_{0} b_{0}^{D *} v^{\prime}\left(b_{0}^{D *}\right) C-\left(1-\pi_{0}\right) v^{\prime}\left(b_{0}^{E *}\right) b_{0}^{E *}
$$

As before, the last term pushes toward the subsidization of early bequests (and thus, toward the taxation of late bequests) since the lowest-income agents are most often dying early. Yet, if they survive to the second period, the poorest individuals are certain to become dependent, which pushes toward the subsidization of late bequests, and thus, toward the taxation of early bequests, in order to redistribute resources toward these agents. Here, one of the challenges of the optimal taxation policy comes from the fact that the taxation of late bequests cannot make the distinction between the dependent agents (who are mostly low-income agents toward whom the government wants to redistribute) and the healthy ones (who are most often richer).

Hence, whether the taxation or the subsidization of early bequests is desirable depends on the relative magnitude of these two opposing forces. Taxation of early bequests is preferable if

$$
\left.\frac{\partial \tilde{\mathcal{L}}}{\partial \tau_{E}}\right|_{\tau_{E}=\tau_{L}=0}>0 \Longleftrightarrow \frac{v^{\prime}\left(b_{0}^{D *}\right)}{v^{\prime}\left(b_{0}^{E *}\right)}>\frac{1}{C} \frac{\left(1-\pi_{0}\right) b_{0}^{E *}}{\pi_{0} b_{0}^{D *}} .
$$

The left-hand side of this inequality represents the ratio of marginal utility from leaving late bequests to the marginal utility from leaving early ones, for the poorest agents. It is always greater than 1 since $b_{0}^{D *}<b_{0}^{E *}$ and it increases with the concavity of the function $v($.$) . It accounts for the insurance effect of increasing early taxation of bequests for the$ poorest agents. To the opposite, the right-hand side of the above inequality gives the ratio of expected early bequests to the expected late bequests left by the poorest individuals weighted by the compensation factor ${ }^{12}$ Equivalently, this term gives the relative participation of the poorest agents to the two taxes in generating fiscal resources and thus, it accounts for the revenue effect of increasing the taxation of early bequests of the poorest agents on overall fiscal resources. It can be greater or smaller than one since $1 / C>1, b_{0}^{E *} / b_{0}^{D *}>1$ but, $\left(1-\pi_{0}\right) / \pi_{0}>1$ if and only if $\pi_{0}$ is relatively small (i.e. $\pi_{0}<1 / 2$ ).

When the above inequality is satisfied, it means that the insurance effect dominates the revenue effect for the poorest agents. For that reason, taxing early bequests (and thus, subsidizing late ones) turns out to be desirable. It enables to increase the utility of the

\footnotetext{
${ }^{12}$ On the denominator of $\sqrt{12}, \pi_{0}\left(1-p_{0}\right) b_{0}^{L *} \rightarrow 0$ when $p_{0} \rightarrow 1$.
} 
poorest individuals, who most often become dependent. In the extreme case where the poorest agents contribute relatively less to the taxation of early bequests than to the taxation of late ones, the RHS of the above inequality is smaller than 1, and a tax on early bequests is then always desirable 13 To the contrary, if the above inequality is reversed, the revenue effect dominates the insurance effect for the poorest agents and, early bequests should be subsidized rather than taxed.

Our results are summarized in the following proposition:

Proposition 4 Assume that the government is Rawlsian. The second-best optimal policy is such that

- If the poorest agent has very low chances to survive $\left(\pi_{0} \rightarrow 0\right)$, it is optimal to tax early bequests.

- If, in case of survival, the poorest agents are almost certain to become dependent $\left(p_{0} \rightarrow\right.$ 0 ), then it is optimal to tax early bequests if the insurance effect of increasing the taxation of early bequests for the poorest agents, dominates its revenue effect.

Finally, let us note that, here again, the concavity of the function $v($.$) plays an important$ role in determining whether the taxation of early bequests is desirable. If relative risk aversion regarding the joy of giving preferences is extreme (the function is extremely concave), the LHS of inequality (12) is much greater than the RHS. In that situation, it is optimal to tax early bequests (rather than late ones), because agents are very risk averse to leaving different levels of bequests. To the opposite, if the individual is risk neutral regarding his joy of giving preferences, the LHS is equal to one and, only if $\pi_{0}$ is very large, we can obtain that early taxation is desirable. However, for reasonable levels of risk aversion, whether the insurance or the revenue effect dominate will depend on the specific levels of the parameters of the model.

\section{Conclusion}

As emphasized in Cremer and Pestieau (2006), the theoretical literature on wealth transfer taxation has been concerned by the distinction between planned and unplanned bequests with the result that the latter should be heavily taxed since it does not entail disincentive effects and can be quite redistributive. Unfortunately, in practice, it is quite difficult to sort out those two types of bequests. One way to overcome this issue would be to differentiate taxation rates according to the timing of bequests, as proposed by Vickrey (1945) and more recently, by Fleurbaey et al. (2019) and Pestieau and Ponthière (2019). Nonetheless, this solution has not yet received a lot of attention both by researchers and by politicians. Even

\footnotetext{
${ }^{13}$ This would be the case if, for instance, $\pi_{0}$ was large.
} 
though this differentiation is possible, the widespread practice around the world involves tax rates on bequests that do not depend on the age of the deceased.

In this paper, we have nonetheless shown that it is socially desirable to make the taxation of bequests depend explicitly on the age of the deceased, while taking into account the fact that some precautionary savings, made because life is uncertain, are also the result of uncertainty regarding the probability to become dependent at the old age. We have shown that one difficulty of implementing an age-differentiated taxation results from the fact that if agents lived long, they could either be dependent or autonomous, a characteristic that the government does not observe. Yet, we are able to overcome that challenge and to provide conditions under which the taxation of early bequests should be preferred over the taxation of late ones. This clearly depends on the social welfare criterion retained, as well as on the correlations between income and socio-demographic characteristics in the society.

Under the Utilitarian social welfare function, we show that taxing early bequests more heavily than late ones would be desirable for efficiency reasons and, because in case of survival, low-income agents are more likely to be dependent, a characteristic that the government cannot observe when implementing age-differentiated taxation. On the other hand, high-income agents are more often long-lived and more often in good health when they survive than low-income ones, which pushes toward a higher taxation of late bequests and thus, a lower taxation of early ones. All in all, whether the taxation of early or late bequests should be fostered depends on the relative size of both the insurance and the redistributive effects.

If the government is Rawlsian, the results are again ambiguous. Under the extreme case where the poorest agents have very low chances to live long, it is then desirable to tax more heavily early bequests than late ones as a way to redistribute toward them. If, alternatively, we assume that in case of survival, their chances to remain autonomous are very low, whether it is optimal to tax early bequests depends on the comparison between the insurance and the revenue effects from increasing the taxation of early bequests for the poorest agents. If they contribute relatively less to the taxation of early bequests than to the taxation of late bequests, or if agents are very averse to leaving different levels of bequests depending on the realization of nature, a tax on early bequests is then found to be always desirable.

Note, finally, that, throughout the paper we have assumed away any public or private LTC insurance or pension annuities. It is obvious that if individuals could purchase actuarially fair LTC insurance or pensions, the difference between early and late bequests would disappear as there would not be anymore unplanned bequests. If those schemes are restricted because of loading costs, missing markets and public regulation, then the qualitative nature of our findings still holds. 


\section{References}

[1] Blumkin, T. and E. Sadka, 2003, Estate taxation with intended and accidental bequests, Journal of Public Economics, 88, 1-21.

[2] Brown, J.R. and A. Finkelstein, 2009, The private market for long-term care insurance in the united states: a review of the evidence, The Journal of Risk and Insurance, 76 (1), 5-29.

[3] Brunner J. and S. Pech, 2012, Optimal Taxation of Bequests in a Model with Initial Wealth, 114 (4), 1368-1392.

[4] Cremer H. and P. Pestieau, 2006, Wealth transfer taxation: a survey of the theoretical literature, Chapter 16 in Handbook of the Economics of Giving, Altruism and Reciprocity, vol. 1, pp. 1107-1134 Elsevier North Holland, Amsterdam.

[5] Cremer, H., F. Gavahri and P. Pestieau, 2012, Accidental Bequests: A Curse for the Rich and a Boon for the Poor, Scandinavian Journal of Economics, 114, 1437-1459.

[6] Cremer H. and P. Pestieau, 2014, Social long-term care insurance and redistribution, International Tax and Public Finance, 21, 955-974.

[7] Cremer H., P. Pestieau and K. Roeder, 2016, Social long-term care insurance with twosided altruism, Research in Economics, 70 (1), 101-109.

[8] García-Miralles E., 2020, The Crucial Role of Social Welfare Criteria and Individual Heterogeneity for Optimal Inheritance Taxation, The B.E. Journal of Economic Analysis \& Policy, Vol. 20 (2), 20190274.

[9] Farhi, E. and I. Werning, 2013, Estate taxation with altruism heterogeneity. American Economic Review, Papers and Proceedings, 103 (3), 489-495.

[10] Fleurbaey, M., M-L. Leroux, P. Pestieau, G. Ponthiere and S. Zuber, 2019, Premature Deaths, Involuntary Bequests and Fairness, CESifo Working Paper No. 6802.

[11] Lefebvre M., Perelman S., Schoenmaeckers J. (2018). Inégalités face à la mort et au risque de dependance. Revue Francaise d'Economie, 33(2), 75-112.

[12] Leroux, M-L., G. Ponthiere and P. Pestieau, 2019, Fair Long-Term Care Insurance, CESifo Working Paper 7660.

[13] Lockwood, L., 2018, Incidental Bequests and the Choice to Self-Insure Late-Life Risks, American Economic Review, 108(9), 2513-2550. 
[14] Nishimura Y. and P. Pestieau, 2016, Efficient taxation with differential risks of dependence and mortality, Economics Bulletin, 36 (1), 52-57.

[15] OECD, 2011, Help Wanted? Providing and Paying for Long-Term Care, OECD Publishing.

[16] OECD, 2018, The Role and Design of Net Wealth Taxes in the OECD, Book number 26. https://doi.org/10.1787/19900538

[17] Pestieau, P. and G. Ponthiere, 2011, The Long Term Care Insurance Puzzle. In Financing Long-Term Care in Europe - Institutions. J. Costa-Font, palgrave macmillan edition.

[18] Pestieau, P. and G. Ponthière, 2019, An age differentiated tax on bequests, in Age Policies - Normative Theory and Proposals, ed. by Greg Bognar and Axel Gosseries, forthcoming.

[19] Pestieau, P. and M. Sato, 2008, Estate Taxation With Both Accidental and Planned Bequests, Asia-Pacific Journal of Accounting \& Economics, 15, 223-240.

[20] Piketty, T. and E. Saez, 2013, A Theory of Optimal Inheritance Taxation, Econometrica, Vol. 81 (5), 1851-1886.

[21] Sheshinski, E., 1972, The Optimal Linear Income-tax, Review of Economic Studies, 39(3), 297-302.

[22] Vickrey, William, 1945, An integrated successions tax. Republished in: R. Arnott, K. Arrow, A. Atkinson and J. Drèze (eds.) (1994). Public Economics. Selected Papers by William Vickrey. Cambridge University Press. 